\title{
Chronic Kidney Disease, Stage 0
}

National Cancer Institute

\section{Source}

National Cancer Institute. Chronic Kidney Disease, Stage O. NCI Thesaurus. Code C80386.

Long-standing and persistent renal disease without kidney damage. 